\title{
LAS COMPETENCIAS DE LOS DELEGADOS DEL GOBIERNO Y DE LOS GOBERNADORES CIVILES EN MATERIA DE PERSONAL: ARTICULACION Y REGIMEN
}

\author{
Por LUIS DE LA MORENA Y DE LA MORENA
}

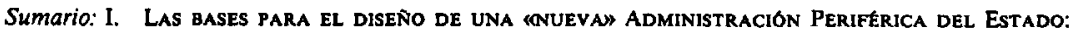
Planteamiento $Y$ exiogncias.-H. Las bases para UNa articulación más Racional dé las COMPETENCIAS SOBRe PERSONAL EN EL SENo de ESTA NUEVA ADMinistración PerifeRICA.-III. REGIMEN JURÍDICO APLICABLE A LOS ACIOS ADMINISTRATIVOS DICTADOS POR LOS DELEGADOS DEL Gobierno y los gobernadores civiles en MATERIa de personal.

I. LAS BASES PARA EL DISEÑo DE UNA «NUEVA» ADMINISTRACIÓN Periferica del Estado: Planteamiento y exigencias

1. Es propósito evidente del Gobierno, y también de las Cortes, en cuanto prolongación legislativa culminadora de su política, el de crear una nueva y, si ello no resultase contradictorio con el proceso autonómico en marcha, también diría que más poderosa, Administración Periférica del Estado.

La forma cómo lograr este milagro no puede ser más clara y elemental: concentrar en torno a las figuras de los delegados del Gobierno y de los gobernadores civiles los restos de Administración Periférica (regional o provincial) que el proceso de transferencias en curso va dejando subsistentes, para levantar sobre ellos una nueva y más pujante Administración Periférica del Estado, que arrumbe, definitivamente, el viejo modelo preautonómico, caracterizado, como es bien sabido, por las diferentes Delegaciones Regionales o Provincia- 
DA-1985, núm. 204. LUIS DE LA MORENA y DE LA MORENA. Las competencias de los Delegados del...

les que cada Ministerio tenia desplazadas por la periferia y a las que ligaba con sus correpondientes órganos centrales a través de una rigida verticalización jerárquica de relaciones, tanto en el plano orgánico como en el funcional.

Urge ganar en calidad lo que se está perdiendo en cantidad; ya no se trata de tener una Administración Periférica muy extensa pero fraccionada, sino una muy intensa y bien vertebrada. Non multi, sed multa, que decian ya, con su vieja sabiduria, los romanos. De esta idea, que es a la vez que idea un consejo práctico, se va a partir. Antes de la reforma en curso, no podia decirse, con rigor, que hubiera una única Administración Periférica del Estado, sino tantas Administraciones Periféricas como Departamentos ministeriales disponian de su propia organización territorial. El poder de fusión o de simple cohesión interna ejercido, entonces, por los gobernadores civiles, en cuanto representantes y delegados del Gobierno y jefes de la Administración Provincial, sobre cada una de estas miniadministraciones, no pasaba de ser un valor entendido, pero no aceptado, y más teórico que real.

Actualmente, las cosas han cambiado y la necesidad de supervivencia, de «ser o no sen» para la Administración Periférica, ha engendrado de nuevo, y está alimentado, un «ideal-exigencia» de integración orgánico-funcional que, sin el impulso del proceso autonómico, volveria a ser inviable. En la etapa preconstitucional, la Administración Periférica del Estado no tenía otros enemigos que pudieran frenar su poder y expansión (las Diputaciones Provinciales, pronto se vio que no lo eran) que su propia división interna y el fuerte centralismo del sistema politico entonces vigente. Ahora, en pleno auge del proceso autonómico, esa Administración Periferica se va a tener que enfrentar (se está enfrentando ya) a otra Administración (la Autonómica, Central y Periférica, a la vez), actuante sobre el mismo territorio, pero dependiente de otro poder legislativo y de otro Gobierno y, por lo mismo, si la sensatez de todos no lo impide, previsiblemente hostil y con pretensiones hegemónicas frente o contra la Administración Territorial del Estado Central.

2. El proceso descrito se inició con el Real Decreto 1801/1981, de 24 de julio, de reforma de la Administración Periférica del Estado que, aparte montar de nueva planta la Administración Regional del Estado, venia a transformar las antiguas Delegaciones Provinciales de cada Ministerio en otras tantas Direcciones Provinciales Departamentales, a 
DA-1985, núm. 204. LUIS DE LA MORENA y DE LA MORENA. Las competencias de los Delegados del...

las que «integraba» en los correspondientes Gobiernos Civiles, y «bajo la autoridad del gobernador civil», pero «sin pérdida de su (previa) dependencia orgánica y funcional de los Ministerios respectivos».

Una tan peregrina integración, capaz de hacerse sin mengua de la preexistente dependencia orgánica y funcional de las Delegaciones integradas respecto de sus correspondientes órganos centrales, vino a constituir, sin duda alguna, el exponente más puro de lo que, en otro lugar, he llamado las «reformas sin cambio», las cuales nos producen la deprimente sensación de que, una vez más, se le está poniendo distinto nombre a la nada. La filosofia inspiradora del citado Real Decreto nos parece, pese a todo, muy clara; la creencia de que las cosas han cambiado o van a cambiar, predispone a que realmente cambien; pero a que cambien «gradualmente», pues no conviene to no se quiere) que este cambio se produzca «de golpe» o «a golpes». (Me remito, en este punto, a mi trabajo «La Administración Periférica: la Reforma que viene... y no llega», en Revista de Administración Pública, número 105, 1984.)

El segurido paso hacia adelante en el proceso integrador emprendido lo dio el Real Decreto 1223/1983, de 4 de mayo, que supuso una «reforma de la reforma», consistente en la supresión de las Direcciones Provinciales Departamentales (creadas escasamente dos años antes por el Real Decreto 1801/1984); supresión que, no obstante, se irá haciendo progresivamente, y no de una sola vez, a medida que el volumen de las funciones y de los sèrvicios traspasados lo vaya haciendo aconsejable, y que conllevará una posterior adscripción orgánica de las Unidades resultantes o no suprimidas a los respectivos Gobiernos Civiles; todo ello, sin perjuicio del mantenimiento de su dependencia funcional previa respecto del correspondiente Ministerio.

Así pues, no sólo se va a seguir «recortando» el primitivo rango orgánico de las antiguas Delegaciones Provinciales (los delegados provinciales llegaron a ser considerados «altos cargos», nombrados en Consejo de Ministros), Delegaciones que podrán pasar ahora a ser simples Secciones o Servicios del correspondiente Gobierno Civil, sino que su doble dependencia orgánica y funcional de los respectivos órganos centrales, celosamente preservada, según vimos, por el Real Decreto $1801 / 1981$, va a quedar reducida, tras la reforma de la reforma, a la exclusivamente funcional. Un ilustrativo ejemplo de esta reforma «por goteo» o en cascada, puesta en marcha lenta por el referido Real 
DA-1985, núm. 204. LUIS DE LA MORENA y DE LA MOREENA. Las competencias de los Delegados del...

Decreto $1223 / 1983$, nos lo proporcionan, por lo que respeta a los Servicios Periféricos dependientes del Ministerio de Educación y Ciencia, los Reales Decretos 2691 y $2692 / 1983$, de 15 de junio, y 2693 y $2694 / 1983$, de 5 de octubre, y, muy especialmente, la Orden de 10 de febrero de 1984, que les sirve de indispensable complemento, y que aparece dictada por Presidencia del Gobierno, a propuesta conjunta de los Ministros de Educación y Ciencia y del Interior. Tal vez, demasiados cocineros para hacer buen caldo.

El tercero y más importante hito de este lento, pero seguro, proceso de reforma y de cambio, viene dado por el decisivo artículo.23, letra c), de la Ley 12/1983, de 14 de octubre, del Proceso Autonómico (importante resto salvado del memorable naufragio de la LOAPA) y, según el cual, «la reforma administrativa (que resulte obligado acometer por efectos del proceso autonómico en marcha) atenderá primordialmente... a la reestructuración de la Administración Periférica... con supresión de las Delegaciones ministeriales (formalmente suprimidas ya en la fecha de su promulgación) y reagrupamiento de los servicios que deban subsistir bajo la autoridad del gobernador civil, que será el único delegado de la Administración del Estado de la provincia».

Este precepto vuelve a adolecer de un grave reparo: el de que no impone, por sí mismo, la reforma que propugna; pero hay que reconocerle una virtud no menos relevante: la de que no va a permitir ya una «vuelta atrás» en la progresión de la reforma, al menos por la via de los simples Reales Decretos. Las Cortes le ordenan al Gobierno que vaya reestructurando la Administración Periférica, pari passu con la marcha del proceso autonómico, lo que es tanto como obligarle a que la haga «sin prisa pero sin pausa», y disponen, además, que esa reestructuración, para que sea legal, tendrá que hacerla el Gobierno tomando como único eje de giro de la misma a los gobernadores civiles o a los delegados del Gobierno, según sea provincial o regional el marco territorial en el que la reforma se efectúe.

II. LAS BASES PARA UNA ARTICULACIÓN MÁS RACIONAL DE LAS COMPETENCIAS SOBRE PERSONAL EN EL SENO DE ESTA NUEVA administración Periférica

1. Sobre este entramado de normas y de propósitos, no siempre coherentes entre sí, vino a incidir la Ley 30/1984, de 2 de agosto, de Medidas para la Reforma de la Función Pública, cuyo artículo 10 
DA-1985, núm. 204. LUIS DE LA MORENA y DE LA MORENA. Las competencias de los Delegados del...

Competencias de personal

dispone que «corresponde a los delegados del Gobierno en relación al personal que haya sido destinado a los Servicios Periféricos de ámbito regional, y a los gobernadores civiles, en relación con el personal destinado a los Servicios Periféricos Provinciales, el ejercicio de las competencias que la legislación vigente atribuye a los subsecretarios y a los directores generales en relación al personal de los Servicios Periféricos de la Administración del Estado, sus Organismos autónomos y de la Seguridad Social, sin perjuicio de la superior dirección que corresponde a los Departamentos ministeriales».

El precepto transcrito ha sido posteriormente desarrollado por el Real Decreto 2169/1984, de 28 de diciembre, cuyo articulo 11 dispone, a su vez, que «corresponden a los subsecretarios de los Ministerios, respecto a los funcionarios destinados en los Servicios Centrales de los mismos y de sus Organismos autónomos y demás Entidades dependientes de los mismos y a los delegados del Gobierno y gobernadores civiles en relación a los funcionarios destinados en servicios periféricos de ámbito regional y provincial, respectivamente, las siguientes competencias:

1) La adscripción provisional, en comisión de servicios a puestos de trabajo por tiempo inferior a seis meses y que no supongan cambio de Ministerio o localidad.

2) Dar posesión y cese a los funcionarios en los puestos de trabajo a que sean destinados.

3) Declarar las jubilaciones forzosas y por incapacidad fisica.

4) La propuesta e informe sobre autorización o reconocimiento de compatibilidades.

5) La concesión de permisos o licencias.

6) El reconocimiento de trienios.

7) La concesión de excedencias voluntarias cuando no sea por interés particular.

8) Atribuir el desempeño provisional de puestos de trabajo en los casos previstos en el artículo 21.2, c), de la Ley 30/1984, de 2 de agosto. Esta competencia será ejercitada por los directores de los Organismos autónomos en relación con el personal funcionario destinado en sus Servicios Centrales».

Importa mucho advertir que la equiparación que en los preceptos transcritos se hace entre las competencias legalmente atribuidas con anterioridad a los subsecretarios y a los directores generales, y las que 
DA-1985, núm. 204. LUIS DE LA MORENA y DE LA MORENA. Las competencias de los Delegados del...

en ellos pasan a atribuirse, a partir de su vigencia, a los delegados del Gobierno y a los gobernadores civiles, no es una equiparación absoluta o total, sino relativa y parcial, y que requiere, por lo mismo, de algunas puntualizaciones previas.

En efecto, los subsecretarios y los directores generales (por cierto, que estos últimos parece que quedan desapoderados de sus competencias en materia de personal, por los artículos $8 .^{\circ}, 4$, y 11 del Real Decreto $2169 / 1984$ ) tiene atribuidas $u$ ostenta, con relación a los delegados del Gobierno y a los gobernadores civiles, un mayor número de competencias (en cantidad e importancia de las mismas), pero en cambio, y paradójicamente, las ejercen sobre un número de «colectivos de funcionarios» (no de funcionarios) mucho mayor y más diferenciado.

Intentemos aclarar esta aparente contradicción. La determinación de las competencias en materia de personal, y su consiguiente atribución para que sean ejercidas a unos órganos o a otros, podrá hacerse tomando como módulo de atribución cualquiera de estos elementos o variables, que enumeramos a título simplemente indicativo:

1) El mero hecho de que se sea funcionario de una clase o de otra (de carrera, contratados, interinos, laborales, eventuales).

2) El encuadramiento orgánico y funcional de la Unidad en que se esté destinado y del puesto de trabajo que en ella se ocupe.

3) El carácter central o periférico de los servicios en los que se esté prestando el trabajo y su ubicación geográfica en una misma o en distintas localidades.

4) La adscripción ministerial a un Departamento u otro del Cuerpo o Escala a los que se pertenezca.

5) El contenido material de la relación funcionarial que en cada caso se considere (disciplinario, retributivo, adscripción de destino o puesto, de definición de situaciones administrativas o de derechos, etc.).

6) La proyección que el ejercicio de cada competencia asignada pueda tener, según trascienda 0 no de la pura organización interna y del normal funcionamiento de los servicios, para efectuar o no a la esfera de los derechos e intereses legalmente protegidos de cada funcionario.

7) Etcétera. 
DA-1985, núm. 204. LUIS DE LA MORENA y DE LA MORENA. Las competencias de los Delegados del...

Pues bien, los delegados del Gobierno y los gobernadores civiles, en cuanto ostentan la Jefatura Superior de (toda) la Administración del Estado en las Comunidades y Provincias de su respectivo mando, (artículos $5 .^{\circ}$ de la Ley $17 / 1983,3 .^{\circ}$ del Real Decreto $1233 / 1983$ y 11 del Real Decreto $3117 / 1980$ ), ejercerán su autoridad sobre (todo) el «personal que haya sido destinado a los servicios periféricos de ámbito regional... o provincial» integrados en aquélla (art. 10 de la Ley 30/1984), con independencia, por lo tanto, de cuál sea el Cuerpo al que cada funcionario pertenezca y cuál la Dirección Provincial Departamental (o unidad que, en su caso, la sustituya) en la que preste sus servicios.

Jefatura y autoridad, la de los delegados del Gobierno y los gobernadores civiles, que se proyectarán, indistintamente, por consiguiente, tanto sobre los servicios que dirijan y coordinen como sobre los funcionarios que en ellos trabajen. A no ser que se disocien, hasta más allá de lo razonable o conveniente, y con evidentes riesgos de distorsión organizativa, la «Jefatura sobre los Servicios» de la «Jefatura sobre el personabs.

Por el contrario, el ámbito al que los subsecretarios de cada Ministerio extienden sus competencias en materia de personal es, territorialmente, más extenso (abarca tanto a los funcionarios destinados en los Servicios Centrales como en los periféricos), pero orgánica y corporativamente más reducido (no podrá trascender a los servicios encuadrados o dependientes de otros Departamentos).

2. De esta dicotomía o disección se deduce, claramente, que los delegados del Gobierno y los gobernadores civiles van a mandar y a ejercer sus competencias en materia de personal sobre un colectivo funcionarial más heterogéneo y complejo (lo que no querrá decir, necesariamente, más numeroso) que el legalmente acotado para que los subsecrétarios ejerzan las suyas. Por otra parte, tanto los delegados del Gobierno como los gobernadores civiles, al representar al todo (esto es, al Gobierno de la Nación), habrá de entenderse que representan también y, necesariamente, a cada uno de los ministros que componen ese todo o Gobierno, los cuales, en buena lógica, y de manera solidaria, deberian refrendar sus nombramientos, análogamente a como se hace en el vecino país con los prefectos.

Las consecuencias extraibles de este planteamiento no pueden ser más evidentes, y las resumimos en estas tres afirmaciones: 
DA-1985, núm. 204. LUIS DE LA MORENA y DE LA MORENA. Las competencias de los Delegados del...

1) En el marco regional o provincial de la Administración Central del Estado no existe otra autoridad ni, por ende, otra representación política con poder decisorio propio, que la de los delegados del Gobierno y los gobernadores civiles, respectivamente. Frente a ellos, el resto del personal sólo merecerá el calificativo jurídico u orgánico de funcionario, cualquiera que sea la función que desempeñe, el Cuerpo al que pertenezca, la categoria que ostente o el nivel retributivo por el que se le pague.

2) Ningún funcionario destinado en las Administraciones Regional o Provincial del Estado [con la sola excepción, si acaso, de los delegados de Hacienda, por tradición, y porque asi lo dispone el art. 23, c), de la Ley 12/1983] podrá sustraerse o autoexcluirse de aquella relación de autoridad y, consiguientemente, de subordinación en que lo hemos situado, respecto de los correspondientes delegados del Gobierno y de los gobernadores civiles, invocando o contraargumentando en su defensa con una supuesta, exclusiva y excluyente «dependencia funcional» respecto de sus correspondientes órganos departamentales o centrales. Para mi es más obvio, por más racional y ajustado al principio de eficacia, que esa conflictiva «dependencia funcional», celosamente defendida aún por los distintos Ministerios sectoriales, no es una dependencia que se haya configurado mirando subjetivamente al conjunto de los funcionarios destinados en los diferentes Servicios regionales o provinciales, sino una dependencia que se ha configurado mirando objetivamente a la autoridad que, en cuanto Jefatura Superior de los mismos, tenga atribuida la obligación y la responsabilidad de dirigirlos y de coordinarlos; Jefatura ésta que no podrá ser otra que la reconocida, con exclusividad, a los delegados del Gobierno y a los gobernadores civiles. Fuera de ellos, los demás funcionarios, sin excepción, se limitarán a ejercer profesionalmente sus funciones en el seno de las Unidades o de los Servicios a los que estén adscritos; Unidades o Servicios que -conviene repetirlo y recordarlo- estarán «orgánicamente integrados») en las correspondientes Delegaciones del Gobierno o en los Gobiernos Civiles respectivos.

Tal será el precio que tendrán que pagar los delegados del Gobierno y los gobernadores civiles por mandar «orgánica- 
DA-1985, núm. 204. LUIS DE LA MORENA y DE LA MORENA. Las competencias de los Delegados del...

mente» sobre todos los funcionarios destinados en sus respectivas demarcaciones territoriales: que todos los ministros $\mathrm{y}$, eventualmente también, todos los secretarios de Estado e, incluso, todos los directores generales responsables directos de cualesquiera servicios sectoriales, manden, a su vez, «funcionalmente» sobre ellos. La jerarquía de la Administración Central sobre la Periférica y la paridad de rango orgánico, dentro de ella, entre unos ministros y otros, asi lo exige.

3) Las competencias que «en materia de personal» o «sobre el personab» corresponderá ejercer a los delegados del Gobierno y a los gobernadores civiles serán de dos clases: a) unas, que mirarán a la denominada, en la conocida terminologia acuñada por el profesor Garcia Trevijano, relación orgánica, en la que lo más característico, a nuestro juicio, es la prioridad atribuible a los interess objetivos de la organización y de sus servicios sobre los derechos y los intereses subjetivos de los funcionarios destinados en ella, y b) otras, que mirarán a la denominada relación de servicio (de arrendamiento y pago de los servicios prestados por cada funcionario a la Administración) en la que, inversamente, lo característico será la prioridad otorgada a los derechos e intereses subjetivos de los funcionarios sobre los intereses objetivos de la organización en cuyas diferentes unidades y servicios se hallen destinados o presten su trabajo aquéllos.

3. Pues bien; tanto el artículo 10 de la Ley 30/1984 como el 10 del Real Decreto 2169/1984, en cuanto genuinas normas reguladoras del Estatuto de los Funcionarios y no de los Estatutos de los diferentes servicios que integran una organización se contraen a enumerar y regular las competencias del grupo segundo o b) del apartado anterior, desconociendo las correspondientes al grupo primero o a).

Aunque la distinción acabada de hacer parezca clara a primera vista, podrá haber, sin embargo, supuestos en los que quepa dudar razonablemente en cuál de los dos grupos encajarlos; tal sucederá, por' ejemplo, con la libre adscripción de los funcionarios, dentro de una misma localidad, a aquellos puestos o unidades en los que más necesarios sean sus servicios para la organización y para el mejor aprovechamiento de sus efectivos. Esta era una competencia anteriormente atribuida, sin 
DA-1985, núm. 204. LUIS DE LA MORENA y DE LA MORENA. Las competencias de los Delegados del...

limitación alguna, al subsecretario o «al jefe de los servicios provinciales correspondientes» (lo que evidenciaba su carácter objetivo o de potestad del jefe a la que debían ceder los derechos subjetivos de los funcionarios) por el artículo 55 del texto articulado de la Ley de Funcionarios de 7 de febrero de 1964, pero que, tras la última reforma, parece haberse limitdo o condicionado por el artículo 10.1 del Real Decreto 2169/1984, a las meras «adscripciones provisionales que no supongan cambio de Ministerio», por más que se efectúen dentro de una misma localidad. Semejante limitación o condicionamiento ha venido a quitar, sin duda, no pocas de sus virtualidades operativas a la integración orgánica de los diferentes servicios periféricos en las Delegaciones del Gobierno y en los Gobiernos Civiles respectivos.

Análogo razonamiento podriamos aplicar a otras cuestiones 0 aspectos en los que resulta igualmente patente su doble conexión, de una parte, con las potestades de dirección inherentes a la jefatura de todos los servicios integrados en una organización, y, de otra, con los derechos o simples intereses de los funcionarios a que no se modifique, sin su consentimiento, su situación personal dentro de la misma, como garantia de igualdad de trato y de no discriminación frente a los demás compañeros no afectados por las decisiones del mando. Entrarian aquí supuestos tales como las reestructuraciones internas de los servicios seguidas de un simultáneo reacoplamiento del personal destinado en ellos, la concesión de permisos y de vacaciones, los turnos de horarios especiales, la distribución de despachos y su correspondiente dotación o equipamiento, la asignación de complementos discrecionales, etc.

Las evidentes contradicciones e incoherencias detectadas hasta aqui entre los planteamientos teórico y práctico que hemos venido exponiendo, nos reafirman, cada vez más, en esta convicción personal: cualquier reforma de la Administración Periférica del Estado que intente acometerse utilizando como único eje de giro a los delegados del Gobierno y a los gobernadores civiles requerirá, para su debida efectividad, esto es, para poder hacerle descender desde el mundo de las ideas al mundo de las realidades, de su plasmación y articulación final en unos pocos y humildes, pero decisivos, instrumentos operativos para una buena, eficaz y unificada administración; a saber, de la previa aprobación y ulterior puesta en práctica de unas plantillas orgánicas y de personal únicas; de unos créditos presupuestarios igualmente únicos con los que retribuir a los funcionarios que, cualquiera que sea su procedencia, Ministerio o Cuerpo, ocupen los diferentes puestos de 
DA-1985, núm. 204. LUIS DE LA MORENA y DE LA MORENA. Las competencias de los Delegados del...

trabajo de aquellas plantillas; de unos locales también únicos 0 , al menos, debidamente interconectados entre sí, en los que ubicar convenientemente los diferentes servicios integrados en la organización; y todo ello servido, finalmente, por el fundente de unos «servicios generales» (personal, habilitación, material, etc.), asimismo únicos, y directamente vinculados a los delegados del Gobierno y a los gobernadores civiles o, por delegación de ellos, a los correspondientes secretarios generales, en cuanto segundos jefes de las respectivas Delegaciones y Gobiernos.

Sólo asi podría acabarse con el espectáculo, nada infrecuente, de que en el seno de una misma organización (la que sirve de cobertura a la Administración Periférica del Estado en su doble escalón regional y provincial), que se supone única por hallarse sometida a la dirección de una única autoridad (la del delegado del Gobierno o el gobernador civil, respectivamente), puedan seguir coexistiendo servicios y unidades orgánicamente integrados en ella, con excedentes de personal y de medios materiales por una más que proporcional reducción de las funciones que tenian encomendadas antes de consumarse los traspasos a la Comunidad Autónoma respectiva, con otros servicios y unidades asimismo integrados orgánicamente en la referida Administración Periférica, pero cuyos efectivos personales y medios materiales siguen resultando notoriamente insuficientes por no haberse visto mermadas sus competencia por dichos traspasos, sino más bien potenciadas por efecto rebote de las mismas.

III. RÉGIMEN JURÍdICO APLICABLE A LOS ACTOS ADMINISTRATIVOS DICTADOS POR LOS DELEGADOS DEL GOBIERNO Y LOS GOBERNADORES CIVILES EN MATERIA DE PERSONAL

1. Examinados en los dos epígrafes precedentes las bases de la nueva Administración Periférica del Estado y la forma más racional y operativa de articular en su seno las competencias en materia de personal, vamos a ocuparnos ahora, en este tercer apartado de nuestro trabajo, del régimen jurídico aplicable a los actos, decisiones o resoluciones administrativas que, en el ejercicio de aquellas competencias, puedan dictar los delegados del Gobierno o los gobernadores civiles; régimen jurídico que vamos a concretar o restrigir al del valor jurídico atribuible a aquellas resoluciones, en función exclusiva de los recursos 
DA-1985, núm. 204. LUIS DE LA MOREN̦A y DE LA MORENA. Las competencias de los Delegados del...

que contra ellas se puedan interponer por los funcionarios destinatarios 0 afectados por las mismas.

Y todo ello sin perder de vista en ningún momento esta premisa o presupuesto argumental: la equiparación inicial establecida por los artículos 10 de la Ley 30/1984 y 11 del Real Decreto $2169 / 1984$ entre las competencias que en materia de personal tenian atribuidas previamente los subsecretarios y los directores generales y las que, por virtud de los mismos, van a pasar a ejercer los delegados del Gobierno y los gobernadores civiles respecto de los funcionarios destinados en los correspondientes servicios regionales o provinciales; equiparación inicial que habrá que puntualizar qué alcance tiene: si el de hacer innecesaria una nueva reproducción de unas competencias objetivas que, se supone, venian ya enumeradas por la legislación anterior, o el de extender, además, a esas competencias objetivas el régimen juridico que, en materia de recursos, se les venia ya aplicando por mandato de otras normas (Ley de Régimen Juridico de la Administración del Estado, Ley reguladora de la Jurisdicción Contencioso-Administrativa, Ley de Procedimiento Administrativo, etc.) que no eran propiamente, ni lo son, normas de personal o sobre el personal.

2. Según el artículo 36.4 de la Ley de Régimen Jurídico de la Administración del Estado, «pondrán fin a la via administrativa las resoluciones... de los subsecretarios y directores generales relativas al personal», por lo que, contra las mismas, no procederá el recurso de alzada (art. 122.1 LPA) y si, únicamente, el de reposición ante ellos mismos (arts. 53.1 LJC y $126.1 \mathrm{LPA}$ ) en aplicación del principio que prohíbe la impugnación contenciosa de un acto administrativo sin antes haberle dado a la Administración una segunda oportunidad, al menos, de revisarlo, ya lo sea ante el superior jerárquico, por vía de alzada (art. 122.2 LPA), ya, cuando ello no sea posible, por agotamiento anormal o anticipado de la vía administrativa (como ocurre en el supuesto que nos ocupa), ante el propio órgano que dictó la resolución, por vía de reposición (art. 53.1 LJC).

Es evidente que el citado artículo 36.4 de la Ley de Régimen Jurídico de la Administración del Estado maneja dos requisitos o módulos: a) el orgánico y b) el material. Por el primero de ellos, limita las resoluciones capaces de agotar la vía administrativa a las que sean dictadas precisamente por los subsecretarios o por los directores generales; por el segundo, a que se refieran a materia de personal y no a ninguna otra. 
DA-1985, núm. 204. LUIS DE LA MORENA y DE LA MORENA. Las competencias de los Delegados del...

La pregunta a la que aquí pretendemos dar cumplida respuesta obligará necesariamente a averiguar si aquellos dos requisitos han de entenderse acumulativos o independientes entre si, o, más claro aún, a preguntarse si bastará que la resolución en cuestión se refiera exclusivamente a materia de personal y no a otra para entender que agotará por si sola la vía administrativa, cualquiera que sea el órgano que la haya podido dictar.

3. Asi enunciado el problema, nos inclinamos por la segunda de las soluciones apuntadas, esto es, por atribuir valor decisorio propio al criterio material sobre el orgánico. Y ello en base a las consideraciones siguientes:

1) El artículo 29 de la Ley de Procedimiento Administrativo obliga a que cualquier duda interpretativa que sưja en materia de «actuación administrativa» (concepto aún más amplio que el de «procedimiento administrativo» en el que habrá que incluir el régimen de los recursos interponibles) se resuelva en el sentido que resulte más favorable a las «normas» (que no sólo «principios») de economia, celeridad y eficacia. Por su parte, el articulo 103.1 de la Constitución sanciona que «la Administración Pública... actúa de acuerdo con los principios de eficacia... y desconcentración», en la medida -se sobreentiende- en que el opuesto principio de «jerarquia» (sancionado igualmente por el referido precepto constitucional) no obligue o imponga, por razones objetivas y suficientemente justificadas, un estricto control jerárquico de los órganos superiores sobre las actuaciones de los órganos inferiores.

Como quiera que es de todo punto evidente que aquellas normas y estos principios postulan antes en favor del agotamiento que de la prolongación de la via administrativa, ésta $-\mathrm{y}$ no otra- deberá ser la solución aplicable ante la duda expuesta.

2) La Ley de Régimen Juridico de la Administración del Estado limita su ámbito de aplicación a los órganos centrales (arts. $3 .^{\circ} \mathrm{y}$ 20), por lo que la no mención de los delegados del Gobierno y de los gobernadores civiles en su artículo 36.4 citado nunca podrá equipararse a una exclusión consciente. Todo ello con independencia de que en la fecha en que la misma se dictó los delegados del Gobierno (entonces inexistentes) y los gobernadores civiles no tenian atribuidas competencias propias en materia 
DA-1985, núm. 204. LUIS DE LA MORENA y DE LA MORENA. Las competencias de los Delegados del...

de personal, al menos las que los textos legales arriba citados han venido a atribuirles después. Tal situación tampoco sería modificada por la Ley posterior $10 / 1983$, de 16 de agosto, que reorganizó de nueva planta la Administración Central del Estado.

Lo que si preveía y disponía la citada Ley de Régimen Juridico de la Adgministración del Estado, en sus disposiciones adicionales primera y segunda, era la conveniencia (que no el mandato) de que los distintos Ministerios elevasen a la Presidencia del Gobierno, en el plazo de un año, «propuestas detalladas sobre los asuntos que... (siendo hasta ahora) de la competencia de los órganos superiores (centrales) puedan ser objeto de desconcentración... (todo ello) con vistas a... conceder... a los delegados provinciales o locales la potestad de resolver definitivamente en via administrativa y con el fin de reducir la materia propia de la competencia de los órganos superiores de los Ministerios".

Es evidente que las competencias desconcentradas -a diferencia de las competencias delegadas- pasan a ser competencias propias o especificas de los órganos en cuyo favor se desconcentren, y precisamente con la finalidad -importa destacarlo- de que los órganos inferiores puedan resolver definitivamente en vía administrativa los asuntos transferidos, cortando asi de raiz la posibilidad de que las competencias desconcentradas puedan posteriormente volver a subir a los órganos que las desconcentraron por la vía retardada de los recursos de alzada interponibles ante los mismos.

Este argumento «desconcentrador» y las consecuencias que la propia Ley de Régimen Juridico de la Administración del Estado extrajo coherentemente de él adquiere hoy un inusitado refuerzo dialéctico al insertarse y operar en un nuevo contexto político que ha venido a consagrar la primacia del principio de desconcentración sobre el de jerarquía y al haberse efectuado la distribución de competencias que ahora nos ocupa no para el desarrollo o cumplimiento de un mandato legislativo previo, sino como expresión significativa de una «nueva política» de organización de servicios y de personal.

Ello obliga a concluir la absoluta inaplicabilidad de la Orden de 10 de julio de 1961 que, sin otra explicación convincente que 
DA-1985, núm. 204. LUIS DE LA MORENA y DE LA MORENA. Las competencias de los Delegados del...

la resistencia de los órganos y de las burocracias centrales a desapoderarse de sus competencias (la competencia es poder y el poder sólo se cede (por las malas»), dispuso que «las resoluciones dictadas por los órganos inferiores en virtud de la desconcentración de funciones... podrán ser objeto de recurso de alzada ante el órgano superior en los mismos casos y términos que las restantes resoluciones emanadas de la competencia propia del órgano inferion. Inaplicabilidad que ya en su día defendió, con contundentes argumentos, el profesor De la Vallina en sus conocidos trabajos sobre la materia, a los que se hace aquí el oportuno reenvio.

3) El procedimiento aplicable en materia de personal tiene esta doble característica: $a$ ) es un procedimiento común o no especial (véase, en confirmación de ello, el Decreto de 10 de octubre de 1958, que únicamente considera procedimiento especial el correspondiente al «régimen disciplinario de la Policia Armada y de Tráficos), y b) es un procedimiento de tramitación simplificada, con tendencia, incluso, a la sumariedad, y ello inclusive en la vía contencioso-administrativa (véanse los arts. 113 a 117 de la Ley reguladora de esta Jurisdicción). Vuelve a deducirse de ello la exigencia lógica de aplicar al problema planteado la solución más favorable a una desconcentración integral o plena.

4) Las competencias que las disposiciones legales citadas atribuyen a los delegados del Gobierno y a los gobernadores civiles se caracterizan, a su vez, por estas dos notas: a) guardan un perfecto paralelismo con las de los subsecretarios y responden a una idéntica política de personal y a un idéntico propósito desconcentrador, y b) tienen en ambos casos, según se ha dicho, el carácter de competencias «propias» y no el de competencias «delegadas», por lo que si está previsto que los actos dictados en el ejercicio de estas últimas agoten la via administrativa (arts. 32.2 y 36.3 LRJ y 93.4 LPA), con mayor motivo deberán agotarla los que se dicten en el ejercicio de competencias propias recibidas directamente de la norma desconcentradora y no de la voluntad, libremente revocable, de su titular (art. 22 LRJ).

5) Finalmente, si se hubiese querido alterar el régimen general vigente sobre recursos interponibles en materia de personal, habria sido necesario que el Real Decreto $2169 / 1984$, al enume- 
DA-1985, núm. 204. LUIS DE LA MORENA y DE LA MORENA. Las competencias de los Delegados del...

rar las competencias de los ministros (art. 9..$^{\circ}$ y de los subsecretarios (arts. $8 .^{\circ}, 4 .^{\circ}, 10$ y 11) hubiese previsto tal posibilidad de recurrir en alzada las resoluciones de los delegados del Gobierno y de los gobernadores civiles, cosa que no hizo, por lo que deberá entenderse que se optó conscientemente por el mantenimiento del régimen impugnatorio general.

4. A la larga serie de argumentaciones expuestas, únicamente podria oponerse una objeción en contrario: la de que, según el artículo 10 de la referida Ley 30/1984, las competencias de los delegados del Gobierno y de los gobernadores civiles en materia de personal se entenderán atribuidas "sin perjuicio de la superior dirección que corresponde a los Departamentos ministeriales», salvedad esta última que no se establece, sin embargo, cuando esas mismas competencias son atribuidas a los subsecretarios y son ejercidas por ellos.

La razón de tal diferencia parece clara; los subsecretarios, como ya dijimos anteriormente, tienen dos clases de competencias en materia de personal: a) unas, "con relación a todos los funcionarios destinados en su Departamento o pertenecientes a Cuerpos o Escalas adscritos al mismo», y tanto si prestan servicio en dependencias centrales como periféricas (las de los arts. $8^{\circ}-4$ y 10 del Real Decreto $2169 / 1984$ ), y b) otras, «respecto de los funcionarios destinados en los servicios centrales» (las del art. 11 del mismo Real Decreto). Pues bien; sólo èstas últimas competencias se corresponden objetivamente con las que a los delegados del Gobierno y a los gobernadores civiles les han sido atribuidas por aquellos textos legales con relación a los funcionarios destinados en los diferentes servicios regionales o provinciales $y$, por consiguiente, únicamente respecto de ellas podrá predicarse la absoluta equiparación de régimen impugnatorio y de recursos que en el presente trabajo mantenemos.

5. A la vista de las consideraciones precedentes, habrá que concluir que el alcance de la referida salvedad, contenida en el artículo 10 de la citada Ley 30/1984, sólo admitirá cualquiera de estas dos interpretaciones:

1) La de entender que «la superior dirección que corresponde a los Departamentos ministeriales» (sin especificar a cuáles de sus órganos centrales: ministros, secretarios de Estado, subsecretarios o directores generales) sobre el ejercicio que de sus competencias hagan los delegados del Gobierno y los goberna- 
DA-1985, núm. 204. LUIS DE LA MORENA y DE LA MORENA. Las competencias de los Delegados del...

dores civiles, sólo podrá referirse a aquellas «actuaciones» de los mismos que no supongan la emanación de auténticas resoluciones, esto es, de «actos decisorios» que, por crear nuevos derechos $u$ obligaciones a favor o en contra de los funcionarios, puedan ser susceptibles de impugnación por los mismos, sino al ejercicio de aquellas otras funciones de organización, gestión, control, estudio o propuesta que, debiendo desarrollarse bajo su dirección y supervisión por las correspondientes unidades de personal, no sean susceptibles de incidir, por su exclusiva referencia, al orden y régimen interno de los servicios sobre la esfera de los derechos $o$ intereses individuales y legalmente protegidos de los funcionarios, haciendo imposible, en consecuencia, su impugnación por ellos.

No seria lo mismo ni mereceria idéntico tratamiento juridico, por ejemplo, la denegación de un permiso concreto a un funcionario concreto y por hechos o circunstancias que le diesen derecho a pedirlo y a obtenerlo, que la elaboración de las normas, criterios, directrices $o$ instrucciones internas que se pretendan seguir para, respetando los derechos de los funcionarios, disponer cómo habrán de sustituirse entre si; de qué trabajos se habrá de responsabilizar cada uno; conforme a qué pautas de actuación deberán desempeñar sus cometidos; cómo se cubrirán entre ellos los turnos de guardia o especiales que vengan exigidos por la buena marcha de los servicios, etc.

2) La de entender, por el contrario (y esta interpretación nos parece la más correcta), que aquella «superior dirección de los correspondientes órganos centrales departamentales sobre las competencias otorgadas a los delegados del Gobierno y a los gobernadore civiles en materia de personal no está haciendo referencia, dentro del conjunto de las potestades directivas integradas en la jerarquía, a la de revisar en alzada las resoluciones de los órganos inferiores posteriormente a ser dictadas, sino a la de dirigir, orientar e impulsar, con carácter previo, sus actuaciones en general por medio de circulares e instrucciones y con anterioridad a que se concreten en actos o resoluciones individuales susceptibles de impugnación aislada.

Una modalidad de este tipo de dirección nos la ofrecía el artículo $70^{\circ}$ de la anterior Ley de Régimen Local (texto refun- 
DA-1985, núm. 204. LUIS DE LA MORENA y DE LA MORENA. Las competencias de los Delegados del...

dido de 1955), según el cual «en las materias que la Ley no confie expresamente a su exclusiva competencia, los municipios y las provincias actuarán bajo la dirección administrativa del Ministerio de la Gobernación" (hoy Interior). Al transformarse la seudodescentralización (realmente jerarquización) prevista en aquella Ley en un regimen de autonomía plena y garantizada, por virtud de lo dispuesto en el artículo 140 de la Constitución, el Tribunal Constitucional, en su sentencia de 2 de febrero de 1981 (suplemento al «Boletín Oficial del Estado» de 24 de febrero siguiente) se veria en la obligación de declarar derogado por ella dicho precepto. Hoy, tras la reciente promulgación de la Ley $7 / 1985$, de 2 de abril, reguladora de las bases de Régimen Local, la imposibilidad legal de ejercer sobre las Corporaciones Locales cualquier tipo de «dirección administrativa» (previa o posterior) aparece expresamente reservada para el caso en que las competencias que aquéllas ejerzan tengan el carácter de «delegadas» (art. 27), pero en ningún caso para las que tengan atribuidas como propias (art. 55).

Si abandonamos la Administración Local para adentrarnos, como por otra parte parece obligado hacerlo, en el ámbito propio de la Administración del Estado (en su doble escalón central y periférico), esa misma modalidad de dirección jerárquica o administrativa previa a la que venimos refiriéndonos. aparece expresamente sancionada en dos textos fundamentales: en el articulo 18 de la Ley de Régimen Juridico de la Administración del Estado, según el cual «los subsecretarios y los directores generales, en cuanto se refiere a la organización interna de los servicios dependientes de los mismos, podrán dictar circulares e instrucciones, y en el artículo $70^{\circ}$ de la Ley de Procedimiento Administrativo que, con mayor laconismo y precisión, dispone que «los órganos superiores podrán dirigir con carácter general (y previo) la actividad de los inferiores mediante instrucciones y circulares».

Resta advertir finalmente que ambas potestades jerárquicas (la de revisar en alzada los actos de los inferiores por razón de su contenido supuestamente ilegal, y la de modular previamente, por medio de instrucciones y circulares, aquel mismo contenido para garantizar que nazca correcto) no se excluyen reciprocamente y que lo normal será, por el contrario, que 
coexistan. Excepcionalmente no sucederá así en aquellas materias o supuestos en los que esté expresamente previsto que los actos de los órganos inferiores agoten la vía administrativa $y$, por consiguiente, no puedan ser revisados en alzada por los órganos superiores. En estos casos, uno de los cuales lo sería precisamente el de los actos dictados por los delegados del Gobierno y por los gobernadores civiles en el ejercicio de sus competencias en materia de personal, la lógica más elemental obligará al legislador a tener que reforzar, por via de compensación, las garantías o controles previos representados por la «dirección administrativa» cuando, conscientemente, haya prescindido o renunciado, por razones de eficacia, a las garantías o controles posteriores representados por las «revisiones en alzada».

Esto es, ni más ni menos, lo que ha hecho sabiamente el último reformador de nuestra legislación sobre personal, al menos en los aspectos concretos a los que hemos contraido el presente estudio. 
DA-1985, núm. 204. LUIS DE LA MORENA y DE LA MORENA. Las competencias de los Delegados del...

DA-1985, núm. 204. LUIS DE LA MORENA y DE LA MORENA. Las competencias de los Delegados del... 
DA-1985, núm. 204. LUIS DE LA MORENA y DE LA MORENA. Las competencias de los Delegados del...

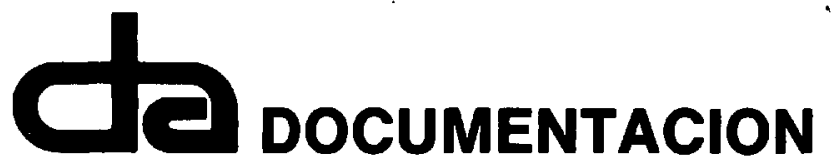

- Documentos parlamentarios

- Notas.

DA-1985, núm. 204. LUIS DE LA MORENA y DE LA MORENA. Las competencias de los Delegados del... 
DA-1985, núm. 204. LUIS DE LA MORENA y DE LA MORENA. Las competencias de los Delegados del...

DA-1985, núm. 204. LUIS DE LA MORENA y DE LA MORENA. Las competencias de los Pelegados del... 